\title{
The effect of cAMP and cGMP on the activity and substrate specificity of protein kinase A from methylotrophic yeast Pichia pastoris
}

\author{
Magdalena Frajnt ${ }^{1}$, Małgorzata Cytryńska ${ }^{2}$ and Teresa Jakubowicz ${ }^{2 凶}$ \\ ${ }^{1}$ Department of Molecular Biology, and ${ }^{2}$ Department of Invertebrate Immunology, \\ Maria Curie-Skłodowska University, Lublin, Poland
}

Received: 15 October, 2003; revised: 24 November, 2003; accepted: 08 December, 2003

Key words: PKA, cAMP, cGMP, protein phosphorylation, yeast

\begin{abstract}
Cyclic AMP dependent protein kinase (PKA) from Pichia pastoris yeast cells was found to be activated by either cAMP or cGMP. Analogs of cAMP such as 8-chloro-cAMP and 8-bromo-cAMP were as potent as cAMP in PKA activation while $N^{6}, 2$-O-dibutyryl-cAMP did not stimulate the enzyme activity. It was shown that protamine sulfate was almost equally phosphorylated in the presence of 1-2 $\times$ $10^{-6}$ M cAMP or cGMP while other substrates such as Kemptide, ribosomal protein $S_{6}$, were phosphorylated to a lower extent in the presence of cGMP. It was demonstrated that pyruvate kinase is a substrate of PKA which co-purified with the $P$. pastoris enzyme. Moreover, pyruvate kinase was phosphorylated by PKA in the presence of cAMP and cGMP to comparable levels.
\end{abstract}

Cyclic AMP dependent protein kinase plays a key role in regulation of basic cellular processes connected with metabolism, growth and differentiation. In yeast PKA is involved in the control of cell cycle progression, induction of thermotolerance, sporulation and survival during starvation conditions (for review see Thevelein et al., 2000). In the absence of cAMP the holoenzyme of PKA exists as a heterotetramer composed of two catalytic (C) and two regulatory (R) subunits. Binding of cAMP to regulatory subunits leads to dissociation of the dimer of regulatory subunits $\left(\mathrm{R}_{2}\right)$ from the catalytic subunit and the released $\mathrm{C}$ subunit is able to phosphorylate serine or threonine residues in cellular proteins. In mammalian cells four isoforms of regulatory subunits and three isoforms of catalytic sub-

\footnotetext{
${ }^{凶}$ Address for correspondence: Teresa Jakubowicz, Department of Invertebrate Immunology, Maria Curie-Skłodowska University, Akademicka 19, 20-033 Lublin, Poland; tel.: (48 81) 537 5089; e-mail: tejak@biotop.umcs.lublin.pl
}

Abbreviations: PKA, cyclic AMP dependent protein kinase; PYK1, pyruvate kinase; MBP, myelin basic protein. 
units, encoded by different genes, were identified (Edelman et al., 1987; Taylor et al., 1990). Expression of these subunits varies in different cells and tissues leading to differential physiological responses to cAMP. In the yeast Saccharomyces cerevisiae catalytic subunits are encoded by TPK1-3 genes (Toda et al., 1987b; Zoller et al., 1988) while the regulatory subunit by a single $B C Y 1$ gene (Cannon et al., 1990; Kunisawa et al., 1987; Toda et al., 1987a). The regulatory subunit plays a major role in regulation of PKA activity. On the basis of biochemical properties such as: (i) amino-acid sequences, (ii) cAMP binding kinetics, (iii) ability to undergo autophosphorylation and (iv) interaction with other macromolecules, two types of regulatory subunits, type I and II, were distinguished (Edelman et al., 1987; Taylor et al., 1990). The yeast Bcy1 protein was classified as type II regulatory subunit (Cannon et al., 1990; Toda et al., 1987a). Recently, the members of the PKA regulatory subunits family were analyzed by multiple sequence alignment and on this basis the phylogenetic trees were generated (Canaves \& Taylor, 2002). The sequence analyses allowed to distinguish four types of $R$ subunits. Two of them correspond to classical type I and II subunits in mammals and the other two to Fungi (type III) and Alveolates (type IV). It was observed that in contrast to type I, II and IV, in the R subunits from fungi (type III) the affinity for cAMP and cGMP varies among the residues. Interestingly, our earlier studies provided experimental evidence that the native PKA holoenzyme purified from $S$. cerevisiae was activated almost equally by cAMP and cGMP (Cytryńska et al., 1999). It was also reported that cGMP and cIMP (Hixson \& Krebs, 1980) are competitive inhibitors of cAMP binding to the $\mathrm{R}$ subunit of PKA from $S$. cerevisiae. Additionally, in light of the finding that the $S$. cerevisiae genome does not contain the gene encoding cGMP dependent protein kinase (Hunter \& Plowman, 1997), it is quite possible that PKA in yeast cells respond to different cyclic nucleotides in signal transduction.

In this paper we present the results on the effect of cAMP, cGMP and selected analogs of cAMP on the activity of PKA from Pichia pastoris yeast cells. Phosphorylation level of different substrates by PKA in the presence of cAMP and cGMP was also analyzed.

\section{MATERIALS AND METHODS}

Strain and growth conditions. Pichia pastoris, strain JC100 (Cregg Lab., Oregon Institute of Science and Technology, Portland, U.S.A.) was grown under aerobic conditions in YPD medium ( $1 \%$ yeast extract, $2 \%$ peptone, $2 \%$ glucose) at $28^{\circ} \mathrm{C}$ to the exponential growth phase.

Purification of cyclic AMP dependent protein kinase. Cell free extracts were prepared in buffer A containing $50 \mathrm{mM}$ Tris/ $\mathrm{HCl}, \mathrm{pH}$ 7.5, $0.5 \mathrm{mM}$ EDTA, $10 \mathrm{mM} \beta$-glycerophosphate, $6 \mathrm{mM}$ 2-mercaptoethanol and 1 $\mathrm{mM}$ phenylmethylsulfonyl fluoride (PMSF), as described previously (Cytryńska et al., 1999). A crude PKA preparation was obtained from the postribosomal cell-free extract by ammonium sulfate precipitation at $55 \%$ saturation. After overnight dialysis against buffer $\mathrm{A}$, the crude PKA preparation containing $1390 \mathrm{mg}$ protein was fractionated on a DEAE-cellulose (DE-52) column equilibrated with the same buffer. Proteins were eluted with a linear gradient of $0-0.5 \mathrm{M} \mathrm{NaCl}$. Protein kinase activity stimulated by cAMP was found in the fractions eluted at 0.06-0.13 $\mathrm{M} \mathrm{NaCl}$. The active fractions were pooled, concentrated on polyethylene glycol 20000 (PEG-20 000) and dialyzed overnight against buffer A. Then the dialysate (432 mg proteins) was applied onto a P-cellulose (P-11) column equilibrated with the above buffer. The proteins were eluted with a linear gradient of 0-0.5 M NaCl. The flow-through fractions containing protein kinase activity stim- 
ulated by cAMP were pooled, concentrated on PEG-20000 and dialyzed overnight against

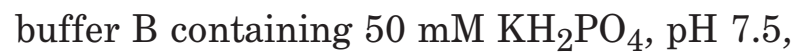
$0.5 \mathrm{mM}$ EDTA, $10 \mathrm{mM} \beta$-glycerophosphate, $6 \mathrm{mM}$ 2-mercaptoethanol and $1 \mathrm{mM}$ PMSF. The proteinous $(212 \mathrm{mg}$ ) dialysate was then applied onto a hydroxyapatite Bio-Gel HTP column equilibrated with the same buffer. Proteins were eluted with a linear gradient of 10-300 mM KH $\mathrm{KO}_{4}$. PKA activity was recovered at 30-100 mM potassium phosphate. The active fractions of PKA were pooled, concentrated on PEG-20000, dialyzed against buffer $\mathrm{A}$ and stored in the same buffer containing $40 \%$ glycerol at $-20^{\circ} \mathrm{C}$. Specific activity of the purified enzyme was $1800 \mathrm{U} / \mathrm{mg}$. One unit of kinase activity was defined as the amount of the enzyme required for incorporation of 1 pmol of phosphate from $\left[\gamma_{-}{ }^{32} \mathrm{P}\right] \mathrm{ATP}$ into the protein substrate (protamine sulfate) per min under optimal conditions.

Protein kinase A assay. The standard reaction mixture $(50 \mu \mathrm{l})$ contained: $20 \mathrm{mM}$ Tris/HCl, $\mathrm{pH} 7.5,10 \mathrm{mM} \mathrm{Mg}\left(\mathrm{CH}_{3} \mathrm{COO}\right)_{2}, 5$ mM 2-mercaptoethanol, $15 \mu \mathrm{g}$ protamine sulfate, $2 \times 10^{-6} \mathrm{M}$ cAMP or cGMP, $0.03 \mathrm{mM}$ $\left[\gamma-{ }^{32} \mathrm{P}\right] \mathrm{ATP}\left(450\right.$ c.p.m. $\times$ pmol $\left.10^{-1}\right)$ and PKA fraction (2-4 $\mu \mathrm{g}$ of protein). After incubation at $30^{\circ} \mathrm{C}$ for 20 min the reaction mixture was spotted onto phosphocellulose filter (Whatman P81) and washed three times in $15 \%$ acetic acid. Radioactivity was determined using a scintillation counter (Cytryńska et al., 2001). Where indicated, $150 \mu \mathrm{g}$ of purified yeast ribosomes instead of protamine sulfate were used as the substrate. The incubations were stopped by addition of $25 \mu \mathrm{l}$ of Laemmli sample buffer (Laemmli, 1970). Ribosomal protein phosphorylation level was analyzed by polyacrylamide gel electrophoresis (SDS/PAGE) and subsequent autoradiography. Autophosphorylation of PKA was measured in the above reaction mixture without exogenous protein substrate and in the presence of $0.09 \mathrm{mM}\left[\gamma_{-}{ }^{32} \mathrm{P}\right] \mathrm{ATP}$. The reaction was stopped by the addition of $25 \mu \mathrm{l}$ of Laemmli sample buffer. The autophospho- rylation level was analyzed as above by SDS/PAGE and autoradiography.

Immunoblotting. Samples of PKA containing $2 \mu \mathrm{g}$ of protein obtained as described were subjected to $12 \%$ SDS/PAGE and the gels were electroblotted onto Immobilon membranes (Millipore) for $60 \mathrm{~min}$ at $150 \mathrm{~V}$. For identification of pyruvate kinase, the membranes were probed with polyclonal antibodies directed to $S$. cerevisiae PYK1 (1:30 000), kindly donated by Professor Jeremy Thorner (University of California, Berkeley, CA, U.S.A.). As second antibodies, alkaline phosphatase-conjugated goat anti-rabbit IgGs were used. Immunoreactive bands were visualized by incubation with $p$-nitroblue tetrazolium chloride and 5-bromo-4-chloro3-indolyl phosphate.

Preparation of purified ribosomes. Yeast microsome fractions (membrane-bound ribosomes) were obtained from cell free extract in buffer A by centrifugation for $1.5 \mathrm{~h}$ at 45000 r.p.m. at $4^{\circ} \mathrm{C}$ in the Beckman Ti 75 rotor. Membrane free ribosomes were released from the endoplasmic reticulum by treatment of the microsome fraction with $1 \%$ Triton X-100. Purified ribosomes were obtained by washing membrane-free ribosomes twice with buffer A containing $0.5 \mathrm{M} \mathrm{KCl}$ and subsequently sedimented through $1 \mathrm{M}$ sucrose in buffer A. Concentration of the purified ribosomes $\left(11 \times A_{260}=1 \mathrm{mg} / \mathrm{ml}\right)$ was estimated according to Van der Zeijst et al. (1972).

Determination of protein concentration. Concentration of protein was determined by the Bradford method (Bradford, 1976) using bovine serum albumin as a standard.

\section{RESULTS AND DISCUSSION}

It is known that in many eukaryotic organisms there are two separate protein kinases stimulated by cAMP (PKA) or cGMP (PKG). On the other hand, we reported that PKA from yeast Saccharomyces cerevisiae can be equally activated by either cAMP or cGMP 
(Cytryńska et al., 1999). Therefore, we were interested in establishing whether this property of $S$. cerevisiae PKA was an exception or a rule for the yeast species. In this paper we present the effect of cAMP and cGMP on PKA activity of methylotrophic yeast Pichia pastoris. The cyclic AMP dependent protein kinase was purified from postribosomal supernatant. The purification procedure included $55 \%$ ammonium sulfate precipitation followed by column chromatography on DEAE-cellulose, P-cellulose and hydroxyapatite (Materials and Methods). PKA was eluted as a single peak at each step of chromatography and showed dependence on addition of cAMP. As seen in Fig. 1 the maximal level of activity was observed at 0.4-2 $\mu \mathrm{M}$ cAMP concentration. In addition it was found that the enzyme can be activated by cGMP. Between $0.2-0.8 \mu \mathrm{M}$ cGMP the PKA activity reached $35-74 \%$ of that stimulated by cAMP. However, at cGMP concentrations of $1-2 \mu \mathrm{M}$, activation of PKA rose to above $80 \%$ of that with cAMP. In addition, the activity of PKA was assayed in the presence of cAMP analogs. The results, summarized in Table 1 , show that among cAMP analogs 8-chloro-cAMP and 8-bromo-cAMP were as effecive as cAMP whereas $N^{6}, 2^{\prime}-O$-dibutyryl-cAMP did not activate the enzyme. These data confirmed results of our previous studies on $S$. cerevisiae (Cytryńska et al., 1999). Interestingly, we now observed an almost equal stimulation of the enzyme by cAMP and cGMP when protamine sulfate was used as the phosphorylation substrate. When protamine sulfate (Table 2) was replaced by other substrates, activation of the enzyme by cGMP was much less efficient than that by cAMP. Phosphorylation of histone $\mathrm{H} 2 \mathrm{~A}$ and histone $\mathrm{H} 3 \mathrm{~S}$ in the presence of cGMP was $40 \%$ and $60 \%$, respectively of that in the presence of cAMP. Much lower phosphorylation level was observed for the synthetic peptide, Kemptide (LRRASLG), containing one serine residue as a phosphate acceptor located in the characteristic for PKA consensus site $(\mathrm{R} / \mathrm{K})(\mathrm{R} / \mathrm{K}) \mathrm{X}(\mathrm{S} / \mathrm{T})$, where $\mathrm{X}$ is any amino acid. Phosphorylation of Kemptide in the presence of cGMP reached $20 \%$ of that detected in the presence of cAMP.

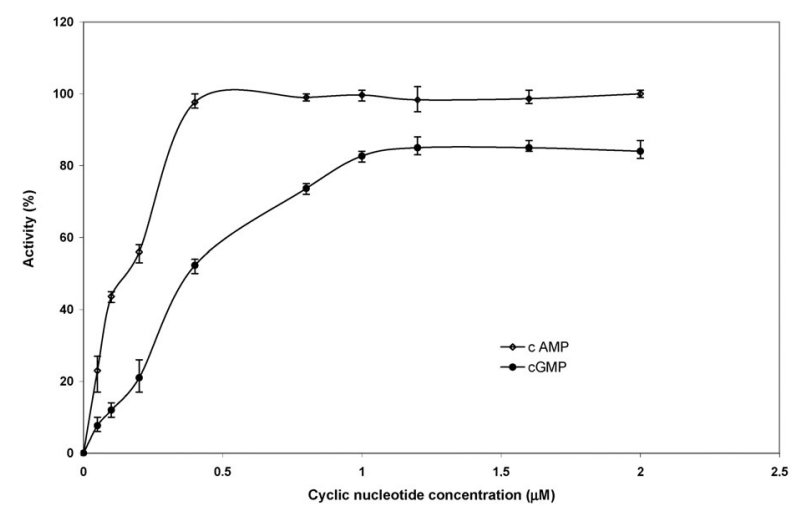

Figure 1. The effect of cAMP and cGMP on protamine sulfate phosphorylation by $P$. pastoris PKA.

Protamine phosphorylation was assayed as described in Materials and Methods in the presence of cAMP or cGMP. The presented results are representative of three independent experiments performed in duplicate. The PKA activity is represented as mean \pm S.D.

The foregoing results were also confirmed by experiments on phosphorylation of $P$. pastoris ribosomal proteins. It was found that PKA, in the presence of cAMP phosphorylated two ribosomal proteins of $30 \mathrm{kDa}$ and $20 \mathrm{kDa}$ (Fig. 2A). However, in the presence of cGMP, phosphorylation level of the 30 $\mathrm{kDa}$ protein was 3-fold lower than that in the presence of cAMP, while phosphorylation of $20 \mathrm{kDa}$ protein in the presence of cGMP was hardly noticeable. Regarding the $30 \mathrm{kDa}$ protein, studies performed in our laboratory, showed that it corresponds to ribosomal protein $\mathrm{S}_{6}$. In $S$. cerevisiae yeast cells $\mathrm{S}_{6}$ is the physiological substrate for cAMP dependent protein kinase (Szyszka \& Gąsior, 1984; Jakubowicz, 1985; Johnson \& Warner, 1987). PKA is known to phosphorylate two serine residues at the $\mathrm{C}$-terminal end of $\mathrm{S}_{6}$ protein.

When a $P$. pastoris PKA sample was incubated with $\left[\gamma-{ }^{32} \mathrm{P}\right] \mathrm{ATP}$ in the presence of cyclic nucleotides without an exogenous phosphorylation substrate (Fig. 2B), a very strong 
phosphorylated band of $56 \mathrm{kDa}$ appeared on the autoradiogram. Phosphorylation of this protein was also observed in Fig. 2A, c and d.

Table 1. The effect of cAMP, cGMP and selected cAMP analogs on the $P$. pastoris PKA.

\begin{tabular}{lc}
\hline Compound & Activity (\%) \\
\hline cAMP & 100.0 \\
cGMP & 98.0 \\
8-bromo-cAMP & 92.0 \\
8-chloro-cAMP & 97.0 \\
$\mathrm{~N}^{6}, 2$ '-O-dibutyryl-cAMP & 2.5 \\
\hline
\end{tabular}

PKA activity was assayed as described in Materials and Methods using protamine sulfate as a phosphorylation substrate. Cyclic nucleotides were used at $2 \times 10^{-6} \mathrm{M}$ concentrations. The presented results are means of three separate experiments performed in duplicate.

It is of interest that similarly as with protamine sulfate, phosphorylation of the $56 \mathrm{kDa}$ protein in the presence of cGMP was as efficient as in the presence of cAMP. These re- al., 2001) that PKA from S. cerevisiae can phosphorylate pyruvate kinase (PYK1) and that PYK1 co-purified with PKA. This led us to suppose that phosphoprotein of $56 \mathrm{kDa}$ from $P$. pastoris can be a pyruvate kinase. When polyclonal antibodies directed to $S$. cerevisiae PYK1 protein were used in immunobloting, a $56 \mathrm{kDa}$ protein was recognized by the antibody in the PKA sample from $P$. pastoris (Fig. 2C, h). This indicates that similarly to $S$. cerevisiae, pyruvate kinase from $P$. pastoris is a phosphorylation substrate co-purifying with PKA. Recent data obtained in Thorner laboratory (Rayner et al., 2002) clearly demonstrated that PYK1 activity in $S$. cerevisiae is regulated by PKA phosphorylation both in vivo and in vitro. To our knowledge no such studies have been performed for P. pastoris.

As shown in Fig. 2B, besides the $56 \mathrm{kDa}$ phosphoprotein there appears a very faint

Table 2. Phosphorylation of different substrates by $P$. pastoris PKA in the presence of cAMP or cGMP.

\begin{tabular}{lccc}
\hline \multirow{2}{*}{ Substrate } & \multicolumn{3}{c}{${ }^{32}$ P-incorporation (pmoles/sample) } \\
\cline { 2 - 4 } & $\begin{array}{c}\text { Without cyclic } \\
\text { nucleotide }\end{array}$ & + cAMP & + +cGMP \\
\hline Casein & 1.7 & 35 & 26 \\
Phosvitin & 1.0 & 34 & 23 \\
Protamine sulfate & 23.0 & 845 & 760 \\
Histone 2A & 22.0 & 304 & 124 \\
Histone H3S & 16.0 & 173 & 100 \\
MBP & 7.2 & 95 & 61 \\
Kemptide & 1.4 & 158 & 33 \\
\hline
\end{tabular}

PKA activity was assayed as described in Materials and Methods using different substrates at the following concentrations: casein $(3 \mathrm{mg} / \mathrm{ml})$, phosvitin $(3 \mathrm{mg} / \mathrm{ml})$, protamine sulfate $(0.3 \mathrm{mg} / \mathrm{ml})$, histone $2 \mathrm{~A}(0.3 \mathrm{mg} / \mathrm{ml})$, histone H3S $(0.3 \mathrm{mg} / \mathrm{ml}), \mathrm{MBP}$ $(0.1 \mathrm{mg} / \mathrm{ml})$, Kemptide $(0.1 \mathrm{mg} / \mathrm{ml})$. Cyclic nucleotides were used at $2 \times 10^{-6} \mathrm{M}$ concentration.

sults seem to indicate that the type of cyclic nucleotide bound (cAMP or cGMP) can somehow affect PKA substrate specificity. This might involve recognition of a different consensus site or serine vs threonine phosphorylation. A more detailed interpretation of these observations requires further studies.

It is worth mentioning that the $56 \mathrm{kDa}$ protein co-purified with $P$. pastoris PKA during column chromatography on DEAE cellulose, P-cellulose and hydroxyapatite. It was recently shown in our laboratory (Cytryńska et
${ }^{32} \mathrm{P}$ radioactive band of $50 \mathrm{kDa}$. This might indicate autophosphorylation of the PKA-R subunit. The ability of the $\mathrm{R}$ subunit to undergo autophosphorylation allow to classify it as type II regulatory subunit (Toda et al., 1987a; Cannon et al., 1990).

Recently, Canaves \& Taylor (2002) used a new method for classification of cAMP-dependent protein kinase regulatory subunit family. On the basis of a multiple alignment of all known sequences, the PKA-R family was divided into four types, I-IV among which 
types I and II correspond to mammals, type III to fungi and type IV to alveolates.

A multiple alignment was used for sequence analysis of the most conserved region of $R$ subunits, the phosphate binding cassette (PBC) of cAMP binding domains. Within the $\mathrm{PBC}$ a signature sequence composed of 14 residues was identified. This approach can be both cyclic nucleotides. Our observations might suggest a residue different from Ala in the signature sequence of $P$. pastoris PKA-R subunit. Unfortunately, its primary structure remains unknown.

It is worth mentioning here that the cGMP level in yeast is about 10-fold (Thevelein \& Beullens, 1985) or even 60-fold (Eckstein,

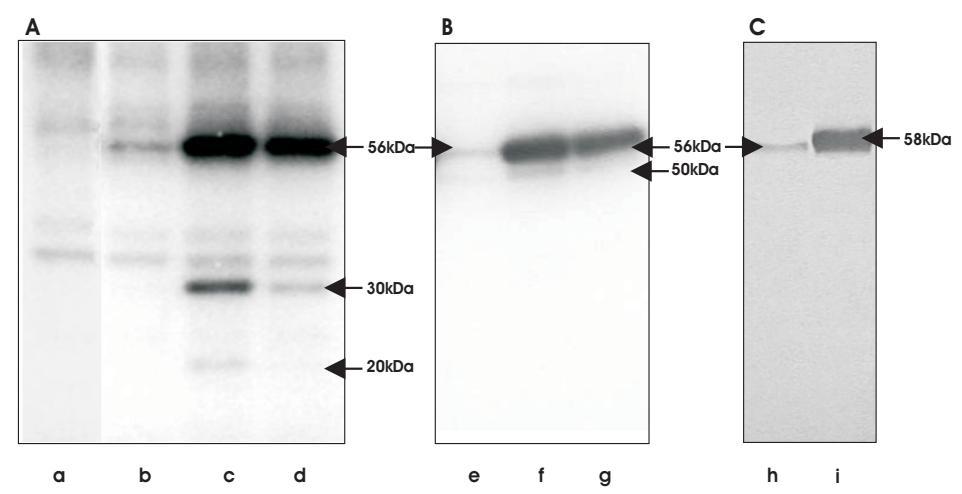

Figure 2. Phosphorylation of ribosomal proteins by $P$. pastoris PKA (A), autophosphorylation (B) and identification of pyruvate kinase by immunoblotting (C) in the $P$. pastoris PKA fraction.

A: Purified ribosomes $(150 \mu \mathrm{g})$ were incubated with $\left[\gamma_{-}^{32} \mathrm{P}\right] \mathrm{ATP}$ alone (a) or with PKA without cyclic nucleotides (b) or with $2 \mu \mathrm{M}$ cAMP (c) or cGMP (d). In A and B phosphorylated proteins were detected by autoradiography. B: PKA fraction was incubated with $\left[\gamma-{ }^{32} \mathrm{P}\right] \mathrm{ATP}$ without exogenous substrate and cyclic nucleotides (e) or with $2 \mu \mathrm{M}$ cAMP (f) or cGMP (g). C: Immunodetection of pyruvate kinase in P. pastoris PKA fraction by anti-PYK1 antibodies (h). Lane i, positive control, showing PYK1 in S. cerevisiae PKA fraction, as described by Cytryńska et al. (2001).

very useful in classification of the PKA-R family members (Canaves \& Taylor, 2002). It was of interest that the residue in position 14 of the signature sequence is important to determine cyclic nucleotide specificity. Replacement of Ala residue in that position with $\mathrm{Thr}$ produces a drastic change in selectivity for cGMP vs cAMP binding (Weber et al., 1989). Analysis performed by Canaves \& Taylor (2002) revealed that the known sequences that do not have an Ala in that position and could potentially be activated by both cAMP and cGMP were found in Blastocladiella (V), S. pombe (N) and Saccharomyces (Q). As shown previously (Cytryńska et al., 1999) PKA from $S$. cerevisiae can also be activated by both cAMP and cGMP. The results presented in this paper clearly indicate that PKA from $P$. pastoris can likewise be activated by
1988) lower in comparison to the level of cAMP. Moreover, no homolog of cGMP-dependent protein kinase was found in the S. cerevisiae genome (Hunter \& Plowman, 1997). Consequently, it is possible that regulation of PKA activity in cellular responses in fungi can be modulated not only by cAMP but also by cGMP and other cyclic nucleotides. These observations encourage further phylogenetic studies on the PKA-R family and also on the evolution of cell signaling mechanisms mediated by cyclic nucleotides.

We would like to thank Monika Koziej and Agnieszka Zdybicka-Barabas for assistance in preparation of the manuscript. 


\section{R E F E R E N C E S}

Canaves JM, Taylor SS. (2002) Classification and phylogenetic analysis of the cAMP-Dependent protein kinase regulatory subunit family. J Mol Evol.; 54: 17-29.

Cannon JF, Gitan R, Tatchell K. (1990) Yeast cAMP-dependent protein kinase regulatory subunit mutations display a variety of phenotypes. J Biol Chem.; 265: 11879-904.

Cytryńska M, Wojda I, Frajnt M, Jakubowicz T. (1999) PKA from Saccharomyces cerevisiae can be activated by cyclic AMP and cyclic GMP. Can J Microbiol.; 45: 31-7.

Cytryńska M, Frajnt M, Jakubowicz T. (2001) Saccharomyces cerevisiae pyruvate kinase Pyk1 is PKA phosphorylation substrate in vitro. FEMS Lett.; 203: 223-7.

Eckstein H. (1988) 3':5'-cyclic GMP in the yeast Saccharomyces cerevisiae at different metabolic conditions. FEBS Lett.; 232: 121-4.

Edelman AM, Blumenthal DK, Krebs EG. (1987) Protein serine/threonine kinases. Annu Rev Biochem.; 56: 567-613.

Hixson CS, Krebs EG. (1980) Characterization of cyclic AMP-binding protein from baker's yeast. J Biol Chem.; 255: 2137-45.

Hunter T, Plowman G. (1997) The protein kinases of budding yeast: six score and more. Trends Biochem Sci.; 22: 18-22.

Jakubowicz T. (1985) Phosphorylation dephosphorylation changes in yeast ribosomal proteins $\mathrm{S}_{2}$ and $\mathrm{S}_{6}$ during growth under normal and hyperthermal conditions. Acta Biochim Polon.; 32: 7-12.

Johnson SP, Warner JR. (1987) Phosphorylation of Saccharomyces cerevisiae equivalent of ribosomal protein $\mathrm{S}_{6}$ has no detectable effect on growth. Mol Cell Biol.; 7: 1338-45.

Kunisawa R, Davis TN, Urdea MS, Thorner J. (1987) Complete nucleotide sequence of the gene encoding the regulatory subunit of 3':5'-cyclic AMP dependent protein kinase from the yeast Saccharomyces cerevisiae. $\mathrm{Nu}$ cleic Acids Res.; 12: 368-9.
Laemmli UK. (1970) Cleavage of structural proteins during the assembly of the head of bacteriophage T4. Nature.; 227: 680-5.

Ogreid D, Ekanger R, Suva RH, Miller JP, Sturm P, Corbin JD, Doskeland SO. (1985) Activation of protein kinase isozymes by cyclic nucleotide analogs used singly or in combination. Principles for optimizing the isozyme specificity of analog combinations. Eur J Biochem.; 150: 219-27.

Rayner TF, Gray JV, Thorner JW. (2002) Direct and novel regulation of cAMP dependent protein kinase by Mck1p, a yeast glycogen synthase kinase-3. J Biol Chem.; 277: 16814-22.

Szyszka R, Gąsior E. (1984) Phosphorylation of ribosomal proteins during differentiation of Saccharomyces cerevisiae. Acta Biochim Polon.; 31: 375-82.

Taylor SS, Buechler JA, Yonemoto W. (1990) cAMP-dependent protein kinase: framework for a diverse family of regulatory enzymes. Annu Rev Biochem.; 59: 971-1005.

Thevelein JM, Beullens M. (1985) Cyclic AMP and the stimulation of trehalase activity in the yeast Saccharomyces cerevisiae by carbon sources, nitrogen sources and inhibitors of protein synthesis. $J$ Gen Microbiol.; 131: 3199-209.

Thevelein JM, Cauwenberg L, Colombo S, De Winde JH, Donation M, Dumortier F, Kraakman L, Lemaire K, Ma P, Nauwelaers D, Rolland F, Teunissen A, Van Dijck P, Versele M, Wera S, Winderickx J. (2000) Nutrient-induced signal transduction through the protein kinase A pathway and its role in the control of metabolism, stress resistance, and growth in yeast. Enzyme Microbial Technol.; 26: 819-25.

Toda T, Cameron S, Sass P, Zoller M, Wigler M. (1987a) Three different genes in $S$. cerevisiae encode the catalytic subunits of the cAMP-dependent protein kinase. Cell.; 50: $277-87$.

Toda T, Cameron S, Sass P, Zoller M, Scott JD, McMullen B, Hurtwitz M, Krebs EG, Wigler M. (1987b) Cloning and characterization of BCY1, a locus encoding a regulatory subunit 
of the cyclic AMP-dependent protein kinase in Saccharomyces cerevisiae. Mol Cell Biol.; 7: 1371-7.

Van der Zeijst BAM, Kool AJ, Bloemers HPJ. (1972) Isolation of active ribosomal subunits from yeast. Eur J Biochem.; 30: 15-25.

Weber IT, Shabb JB, Corbin JD. (1989) Predicted structures of the cGMP binding domains of the cGMP dependent protein kinase
- a key alanine threonine difference in evolutionary divergence of cAMP and cGMP binding sites. Biochemistry.; 28: 6122-7.

Zoller MJ, Kuret J, Cameron S, Levin L, Johnson KE. (1988) Purification and characterization of $\mathrm{C}_{1}$, the catalytic subunit of Saccharomyces cerevisiae cAMP-dependent protein kinase encoded by TPK1. $J$ Biol Chem.; 263: 9142-8. 